\title{
INTRA-ARTERIAL REGIONAL ANAESTHESIA (IARA) - A PERIPHERAL EXPERIENCE
}

\author{
S. Parthasarathy ${ }^{1}$ M. Ravishankar ${ }^{2}$ \\ Chief anaesthesiologist, Govt. Dist. Headquarters hospital, \\ Kumbakonam-612001-Tamilnadu ${ }^{1}$, Prof. and Head, Dept. of anaesthesiology, \\ Mahatma Gandhi Medical College and Research Institute, Pondicherry ${ }^{2}$. \\ *Corresponding author : painfreepartha@gmail.com
}

Key words: Intra-arterial regional anaesthesia, lignocaine

\begin{abstract}
Summary:
Intravenous regional anaesthesia is a simple, safe technique of anaesthesia of extremities for short procedures. The major fear with the use of the technique is local anaesthetic toxicity associated with high volumes of local anaesthetic used. Hence we decided to use reduced volume of local anaesthetic in the peripheral artery to produce satisfactory anaesthesia. A total of twelve patients scheduled to undergo short procedures of upper limb were taken for this study. After exsanguination and tourniquet application on the arm $1.5 \mathrm{mg} / \mathrm{kg}$ of preservative free lignocaine as $0.5 \%$ solution was injected into the cannulated radial artery. The onset of analgesia was $89.92 \pm 17.54$ seconds. The anaesthesia was satisfactory in all cases except in two patients where there was a minimal discomfort with bony manipulation, which settled with $20 \mathrm{mg}$ of iv pentazocine. The mean duration of surgery was $34.54 \pm 4.5$ minutes. The mean volume of lignocaine used was only $15.58 \pm 0.95 \mathrm{ml}$. No significant side effects were noted. We conclude that intraarterial regional anaesthesia is a useful procedure in patients where there is a fear about local anaesthetic toxicity and the problem of difficult venous access.
\end{abstract}

Intravenous regional anaesthesia (IVRA) is a relatively safe and effective way to provide analgesia for upper extremity surgeries ${ }^{1}$. The biggest disadvantage with the use of IVRA is administration of high volumes of local

anaesthetic and its inherent complications ${ }^{2}$. There are situations where iv access may be difficult in wanton places for IVRA. In these circumstances, a peripheral artery can be cannulated and drug can be administered. There is a distinct advantage of using nearly half the

dose when compared to IVRA. Hence we decided to use $0.5 \%$ lignocaine as intra-arterial regional anaesthetic technique (IARA) and study the effects and side effects.

\section{Material and methods.}

Twelve patients of ASA 1 and II posted for minor surgeries of the upper extremity were selected for the study. After approval from the institutional committee and informed patient consent, the patients who were posted for minor surgeries of upper extremity were selected. It included ulnar plating, ganglion excision, nailing and debridement. Preoperative check up and investigations were normal and non-contributory. A modified Allen's test was performed on all cases and found to be satisfactory for arterial cannulation. A $20 \mathrm{G}$ venflon was introduced in the other hand and Inj. diazepam $0.1 \mathrm{mg} / \mathrm{kg}$ with $0.3 \mathrm{mg}$ of atropine was administered iv as premedication. Under aseptic conditions, following local anaesthesia, another 20G cannula was introduced in the affected limb's radial artery. Routine resuscitative measures were kept ready. ECG and pulse oximeter along with the sphygmomanometer were the monitors used. Tourniquet was inflated to $50 \mathrm{~mm} \mathrm{Hg}$ above the systolic pressure. $1.5 \mathrm{mg} / \mathrm{kg}$ of preservative free $0.5 \%$ lignocaine was injected into the radial artery cannula. The onset of analgesia, comfort of the 
patient and the need for additional analgesics and anaesthetics were noted. All data were entered in a proforma and analysed.

\section{Results:}

The demographic data is tabled in table 1 . Table 1 showing demographic profile.

\begin{tabular}{|l|l|}
\hline & Mean \pm std. dev. \\
\hline Age (Years) & $49.25 \pm 7.82$ \\
\hline Weight $($ Kg) & $51.75 \pm 3.67$ \\
\hline
\end{tabular}

After routine exsanguination for five minutes, tourniquet was inflated to $50 \mathrm{mmHg}$ above the systolic blood pressure. All the patients were administered local anaesthetic in the artery. There was no pain on injection in any of the patients. The onset of action was $89.92 \pm 17.54$ seconds i.e. within two minutes of the completion of injection. The mean volume of injectate was $15.58 \pm 0.95 \mathrm{ml}$. Ten patients had satisfactory anaesthesia during the procedure and there were no complaints. Two complained of mild discomfort during bony manipulation and needed $20 \mathrm{mg}$ of iv pentazocine to counter the same. There was no necessity of conversion to controlled General anaesthesia or a need of anaesthetics like propofol or ketamine in any of the patients. The mean duration of surgery was $34.54 \pm 4.5$ minutes. There were no complaints of tourniquet pain in any of the patients. The arterial cannula was removed at the end of the procedure five minutes after deflation of tourniquet. There were no complications with arterial cannulation in any of the patients.

\section{Discussion:}

IVRA, a simple method of providing anaesthesia of the distal arm or leg was first described by August Bier in 1808. After a period of wide popularity, it fell into disuse until popularised again by Holmes in 1963 . $^{3}$ The most important complication is due to the toxicity of local anaesthetics and will occur if the tourniquet suddenly deflates soon after the local anaesthetic has been injected. These will range from dizziness and tinnitus to muscle twitching, loss of consciousness and convulsions. ${ }^{4}$ The usual drug injectate will be around $50 \mathrm{ml}$ of $0.5 \%$ lignocaine. This problem can be lessened if the volume of the local anaesthetic used is less. This is possible when the artery is chosen instead of the vein. Abel
$\mathrm{M}^{5}$ initially found anaesthesia by an accidental injection of sodium escinate into the artery. Nielson ${ }^{6}$ et al used fifteen $\mathrm{ml}$ of $0.5 \%$ lignocaine in the radial artery to provide analgesia for hand surgery in an elderly arthritic female patient. She experienced only minimal discomfort during injection and analgesia was excellent. No untoward effects were observed. They recommended this technique when other methods of regional analgesia are unavailable. We also used $15.58 \mathrm{ml}$ of the drug, which goes along with their observations. Nielson ${ }^{7}$ et al in another study concluded that alkalinized $0.5 \%$ lignocaine was less painful on injection than normal lignocaine and should be preferred for intra-arterial regional anaesthesia for hand surgery. We did not use alkali but preservative free lignocaine was used. There was a mild sensation of warmth during the injection and there was neither pain nor discomfort. Koscielniak-Nielsen $\mathrm{ZJ}{ }^{8}$ in yet another study preferred radial instead of brachial artery to get better results and we used radial artery in all our cases. There was no complication in any of the previous studies, which goes along with our findings. They also observed that $1.5 \mathrm{mg} / \mathrm{kg}$ of $0.5 \%$ lignocaine, as IARA was similar to $3 \mathrm{mg} / \mathrm{kg}$ of lignocaine as IVRA ${ }^{9,10}$. A $50 \%$ incidence of central nervous system toxicity with the use of $3 \mathrm{mg} / \mathrm{kg}$ of lignocaine and $15 \%$ incidence of cardiovascular effects were reported with IVRA. ${ }^{11,12}$ This assumes significance due to the fact that only half the dose of local anaesthetic is used in IARA. In our study we did use only 1.5 $\mathrm{mg} / \mathrm{kg}$ to get adequate analgesia in all patients. The mechanism of action of IVRA is unclear. It is postulated that the vascular bed around the antecubital fossa is very near the nerve trunks to produce anaesthesia. ${ }^{13}$ As the arterial route needs less volume, we can propose that this route produces higher concentrations in the proposed vascular bed, but the statement needs more studies for authenticity. Ours is a small study sample of an ongoing study.This is not a comparative study and we have not compared the effects and side effects with equianalgesic doses of IVRA in a double blind manner.

Still we conclude that

- IARA is a useful technique with only 1.5 $\mathrm{mg} / \mathrm{kg}$ of lignocaine 
- When there is fear of local anaesthetic toxicity, the technique can be thought of.

- This is useful when the venous access is difficult in wanton areas or in drug addicts where there is difficult venous access.

\section{References:}

1. S. Sen , B. Ugur O. Aydın, M. Ogurlu, E. and O. Savk The analgesic effect of lornoxicam when added to lidocaine for intravenous regional anaesthesia. British Journal of Anaesthesia 97 (3): 2006 408-13.

2. Eli M. Brown, James T. McGriff Robert W. Malinowski MDJ Intravenous regional anaesthesia (Bier block): review of 20 years' experience .Can J Anaesth 1989:36:3; 307-10

3. Holmes CM. Intravenous regional anaesthesia. A useful method of producing analgesia of the limbs. Lancet 1963; 1: 245-7.

4. Brill S, Middleton W, Brill G, Fisher A. Bier's block; 100 years old and still going strong! Acta Anaesthesiol Scand 2004; 48: 117-22

5. Abel M, Salm R, Goth D. Therapeutic regional anaesthesia following an accidental intraarterial injection. A case report on anaesthesiology care following incorrect injection of Reparil (sodium escinate) Anaesthetist. 1983 Oct; 32(10): 494-7.

6. Koscielniak-Nielsen Z J, Pederson MD, Intraarterial regional anaesthesia of the hand. British Journal of Anaesthesia, 1991, Vol. 66, No. $6719-720$
7. Koscielniak-Nielsen ZJ, Stens Pederson HL. Intra-arterial regional anaesthesia for hand surgery with alkalinized $0.5 \%$ lignocaine Acta anaesthesiologica Scandinavia 1995, vol. 39, no8, 1048-1052

8. Koscielniak-Nielsen ZJ, Horn A. Radial or brachial artery injections for intraarterial regional anaesthesia for hand surgery? Reg Anesth. 1994 Nov-Dec; 19(6): 402-7.

9. Koscielniak-Nielsen Z J; Hesselbjerg L Intraarterial regional anaesthesia for hand surgery: a dose-finding study Acta anaesthesiologica scandinavica1997, Feb; 41(2): 197-203

10. Koscielniak-Nielsen ZJ, Horn A. Intra-arterial versus intravenous regional analgesia for hand surgery. Anaesthesia. 1993 Sep; 48(9): 769-72.

11. Bell HM, SlaterEM, Harris WH. Regional anaesthesia with intravenous lidocaine. JAMA $1963 ; 186,554$.

12. Kennedy BR, Duthie AM, ParbrookGD and Carr TL.Intravenous regional anaesthesia an appraisal.Br.Med.J 1965,1.954.

13. Risdall, Young, Jones, Hett. A comparison of intercuff and single cuff techniques of intravenous regional anaesthesia using $0.5 \%$ prilocaine mixed with technetium $99 \mathrm{~m}$ labelled BRIDA. 